\title{
Caracterização do consumo de carne suína da população de Xanxerê, Santa Catarina, Brasil
}

\author{
Characterization of pork meat consumption of the population of Xanxerê, Santa Catarina, Brazil
}

\author{
Jackeline Karsten Kirinus ${ }^{1 *}$, Matheus Benedetti ${ }^{1}$, Ander Téo ${ }^{1}$, Willian Pavlik ${ }^{1}$, \\ Gustavo Vinicius Taffarel ${ }^{1}$, Camila de Oliveira Belmonte ${ }^{1}$ e Andrea Cristina Dörr ${ }^{2}$
}

\author{
${ }^{1}$ Departamento de Medicina Veterinária, Campus Xanxerê II, Universidade do Oeste de Santa Catarina (UNOESC), \\ Xanxerê, SC, Brasil. \\ 2 Departamento de Educação Agrícola e Extensão Rural (DEAER), Centro de Ciências Rurais (CCR), Universidade Federal \\ de Santa Maria (UFSM), Santa Maria, RS, Brasil. \\ *E_mail para correspondência: jackeline.kirinus@gmail.com
}

\begin{abstract}
Resumo
A suinocultura destaca-se em algumas regiões do Brasil e mais especificamente, em Santa Catarina, principalmente por possuir a liderança nacional no abate desses animais. Este estudo constitui-se numa ferramenta de grande importância, visto que a identificação dos principais cortes consumidos e análise do que significa carne com alto grau de qualidade para o consumidor Xanxerense, permitirá identificar o perfil do consumidor e contribuir para o sistema de produção dos produtos cárneos. Foi utilizada a pesquisa de campo com coleta de dados primários através de formulários aplicados aos consumidores de carne suína de Xanxerê. Do total de entrevistados, 93,3\% afirmaram consumir carne suína. Ademais, observou-se que a grande parte das pessoas auferem uma renda familiar ou pessoal de 2 a 5 salários mínimos em reais. A costela foi o principal corte de preferência dos entrevistados. Ainda, constatou-se que a aparência clara e menor quantidade de gordura visível são características que influenciam no alto grau de qualidade da carne suína para homens e mulheres, respectivamente. Portanto, faz-se necessário investir em ações que demonstrem os fatores socioeconômicos envolvidos no consumo da carne suína, além de estudos que analisem a qualidade do produto e o real impacto ambiental gerado com a sua produção.
\end{abstract}

Palavras-chave: Consumidores. Entrevistas. Proteína Animal. Questionários. Suinocultura.

\begin{abstract}
The swine stands out in some regions of Brazil and more specifically, in Santa Catarina, mainly by having national leadership in the slaughter of these animals. This study constitutes a very important tool, since the identification of the main consumed cuts and analysis of what it means meat with high quality for the consumer Xanxerense, will identify the user profile and contribute to the production system products meat. Field research with primary data collection using forms applied to pork consumers Xanxerê was used. Of the interviewed, 93.3\% reported consuming pork meat. Moreover, it was observed that most of the people receive a personal or family income 2-5 the minimum wage in real. The rib was the main cutting preference. Further, it was found that the clear appearance and visible fat are features that influence the high degree of quality of pork meat for men and women, respectively. Therefore, it is necessary to invest in actions that demonstrate the socio-economic factors involved in the consumption of pork, as well as studies that analyze the quality of the product and the real environmental impact with its production.
\end{abstract}

Keywords: Animal protein, consumers, interviews, questionnaires, farming pig. 


\section{Introdução}

Atualmente, a carne suína é a carne animal mais consumida no mundo, perfazendo 39\%, ou seja, quase metade da oferta total (Sales et al., 2013). Diante deste contexto, a suinocultura destaca-se em algumas regiões do Brasil e mais especificamente, em Santa Catarina, principalmente por possuir a liderança nacional no abate desses animais (Weydmann et al., 2008). Ora, essa posição catarinense deve-se largamente ao envolvimento da região oeste nessa atividade (Sehnem \& Garrido, 2013).

De acordo com o levantamento sistemático da produção e abates de suínos pela Associação Brasileira de Indústria Produtora e Exportadora de carne suína (ABIPECS, 2014), a região Sul do Brasil representa $65,9 \%$ do abate de suíno nacional, sendo que o estado de Santa Catarina contribui com 26,4\% do total de 39,3 milhões de cabeças de suínos no ano de 2013 (Conab, 2013).

No entanto, apesar de toda a quantidade e qualidade de carne suína brasileira ser obtida por meio de avanços tecnológicos, ainda existem inúmeras restrições por parte da população em relação ao consumo dessa proteína, principalmente relacionados a desinformação e "mitos" tradicionais dos processos produtivos e ambientais deste produto (Sarcinelli, 2007; Dias, 2011).

Neste sentido, vários estudos envolvendo o comportamento do consumo de carne de suína já foram realizados no país (Bezerra et al. 2007; Santos et al., 2011; Santos, 2012.). Assim, devido a necessidade do mercado consumidor em avaliar a carne produzida, faz-se necessário conhecer as características econômicas do produto a ser consumido, assim como correlacionar e analisar as faixas etárias dos consumidores, escolaridade e suas respectivas rendas familiares.

Este estudo constitui-se numa ferramenta de grande importância, visto que a identificação dos principais cortes consumidos e análise do que significa carne com alto grau de qualidade para o consumidor Xanxerense, permitirá identificar o perfil deste e contribuir para o sistema de produção dos produtos cárneos.

\section{Material e métodos}

Para a realização deste trabalho foi utilizada a pesquisa de campo com coleta de dados primários através de formulários aplicados aos consumidores de carne suína de Xanxerê, Santa Catarina, Brasil no período de agosto a dezembro de 2014. Para que a amostragem seja uniforme, optou-se por entrevistar os consumidores diretamente nas gôndolas dos quatro maiores supermercados da cidade.

A amostragem é uma ferramenta estatística utilizada quando a população (conjunto total dos elementos que se busca analisar) é composta por um número muito grande de elementos, o que impossibilita o acesso a toda a população para a coleta dos dados. Assim, uma amostra é selecionada, com número e característica significativos de elementos dentro da população, para que os resultados da amostra sejam suficientemente informativos para se inferir conclusões a cerca de parâmetros de toda a população em análise (Levy \& Lemeshow, 2009).

Foi utilizada a técnica de amostragem aleatória simples, para população finita e conhecida, conforme Barbetta (2008). Para a determinação do tamanho da amostra foi realizada uma pesquisa piloto com 30 integrantes, a fim de obter as informações necessárias para o cálculo com um nível de confiança de $95 \%$. Para fins de cálculo, foi utilizado o desvio padrão $(0,413)$ e a média em quilogramas de carne suína consumido por semana $(0,71 \mathrm{Kg})$. A população do município de Xanxerê totalizou em 47.679 habitantes no ano de 2014 (IBGE, 2014). Dessa forma, foram realizadas 255 entrevistas completas.

Posteriormente, após a aplicação dos questionários, os dados foram tabelados e analisados. A qualidade dos dados coletados foi satisfatória, considerando-se que os entrevistados estavam 
preocupados em fornecer respostas com profundidade. Assim, conseguiu-se levantar com bastante facilidade, por exemplo, a renda mensal (Trespalacios et al., 2005).

A análise foi elaborada através do Pacote Estatístico para as Ciências Sociais - Statistical Package for the Social Sciences (SPSS) versão 14.0 com auxilio dos métodos Chi quadrado e desvio padrão. Os valores foram considerados estatisticamente significantes quando $\mathrm{p}<0,05$.

\section{Resultados e discussão}

Do total de entrevistados, 93,3\% (238/255) afirmaram consumir carne suína, enquanto somente $6,7 \%(17 / 255)$ falaram que não consomem. Estes dados estão de acordo com os observados nos estudos realizados por Merlini et al. (2014) e Antonangelo et al. (2011). Ademais, segundo a Food and Agriculture Organization (2015), estima-se que 36\% da carne mundial consumida é de origem suína.

Conforme a Tabela 1, o número de pessoas abordadas foi caracterizado por renda familiar ou pessoal, em salários mínimos (em reais), estudo e idade (em anos) conforme os sexos masculino e feminino. Verificou-se que a média de idade e anos de estudos dos entrevistados foi respectivamente de 39,24 e 11,57 e que maioria dos questionados possui $2^{\circ}$ grau completo. Também, estes resultados corroboram com o estudo realizado por Taffarel et al. (2013), em que $43 \%$ das pessoas têm ensino médio completo e $37 \%$ recebem entre dois e cinco salários mínimos.

Obtou-se por realizar as entrevistas nas gôndulas dos supermercados tendo em vista a busca pela fidelização das respostas, assim como evitar as possíveis interferências nas variáveis analisadas durante as entrevistas. Barcellos et al. (2012) comprovou que a maioria dos consumidores de carne realizam a compra em supermercados ou hipermercados devido a facilidade, presença de sistemas de Inspeção Federal (SIF) e garantia de origem e marcas dos produtos.

Tabela 1 - Perfil dos consumidores de carne suína entrevistados

\section{VARIÁVEL}

\section{Idade em anos}

Menos de 20

21 a 30

31 a 40

41 a 50

51 a 60

Mais de 60

Escolaridade

Não estudou

$1^{\circ}$ grau incompleto

$1^{\circ}$ grau completo

$2^{\mathrm{o}}$ grau incompleto

$2^{\underline{0}}$ grau completo

$3^{\circ}$ grau incompleto

$3^{\circ}$ grau completo

Pós-graduação incompleta

Pós-graduação completa

Renda familiar (salários mínimos)

Menos de 2

2 a 5

5 a 10

10 a 15

Mais de 15
MASCULINO

134/255

14,2

23,9

14,9

19,4

17,9

9,7

0,7

11,2

13,5

11,9

31,4

12,7

9,7

2,2

6,7

17,2

49,3

26,8

4,5

2,2
FEMININO

121/255

(\%)

10,7

25,6

19,0

18,2

14,9

11,6

(\%)

0,0

19,0

6,6

5,0

24,1

14,0

16,5

4,1

10,7

(\%)

23,9

50,4

18,2

5,0

2,5 
Quando questionados sobre qual o tipo de carne que acreditam ter maior benefício para a saúde, os entrevistados consideraram como primeira escolha a carne de peixe (Tabela 2). De acordo com Soares \& Belo (2015), o pescado é um alimento que se destaca pelo valor nutricional quanto à quantidade e qualidade das suas proteínas, à presença de vitaminas e minerais e, principalmente, por ser fonte de ácidos graxos essenciais ômega-3 eicosapentaenoico (EPA) e docosaexaenoico (DHA).

Por outro lado, a ampliação do consumo da carne suína ainda esbarra em conceitos errôneos, dentre eles, o de que a carne suína é gordurosa e faz mal à saúde (Faria et al., 2006). Estes conceitos errôneos sobre a carne suína devem-se principalmente ao desconhecimento por parte da população dos diferentes trabalhos que incentivam a melhoria genética, manejo ambiental, produção, nutrição e sanidade dos animais durante os últimos anos (Grunert et al., 2006; Roppa, 2011). Alguns autores dizem que o maior entrave no consumo deste produto cárneo pode estar atrelado à falta de investimentos em marketing (Silva \& Silva, 2009), pois grande parte das pessoas não tem conhecimento sobre a qualidade nutricional desta fonte de proteína.

Ainda segundo Schlindwein \& Kassouf (2006) e Kirinus et al. (2013), o menor consumo de carne suína em relação ao consumo de outras carnes está atribuído principalmente a dois fatores: a importância que a população atribui aos mitos relacionados a prováveis impactos negativos do consumo da carne suína sobre a saúde, e a falta de cortes específicos de baixo valor agregado (acessíveis à população de baixa renda).

Neste sentido, os entrevistados foram questionados sobre a preferência dos cortes. Observou-se que $54,7 \%$ destes demonstraram preferência e compra pelo corte da costela na forma assada. Este resultado contraria os obtidos por Antonangelo et al. (2011) e Merlini et al. (2014), onde 16,6\% e $33,6 \%$, respectivamente dos consumidores afirmaram que a bisteca e lombo são os cortes que mais aparecem em seus cardápios. Também, Silva e Silva (2009) mostrou que 39\% dos entrevistados elegeram a bisteca como corte comercial de maior preferência. Por outro lado, a costela foi a terceira escolha no estudo realizado por Taffarel et al. (2013) no município de Lavras, Minas Gerais.

Dos homens e mulheres questionados, 52,2\% e 41,3\% respectivamente, atribuíram a escolha da preferência e compra da costela devido a característica do sabor que o corte apresenta. Segundo pesquisa realizada por Faria et al. (2006) e Taffarel et al. (2013), o sabor foi o principal motivo para o consumo da carne suína, seguido pela variação no cardápio e pela facilidade na compra. Ademais, no estudo realizado por Thoms et al. (2010), 66\% dos acadêmicos entrevistados informaram que o sabor da carne suína era o atributo mais influente na compra deste produto.

Além disso, ambos os sexos compram a carne suína no supermercado e escolheram este local para compra devido a facilidade de encontrar o produto. Estes dados são diferentes dos encontrados por Bezerra et al (2007), onde a limpeza e higiene do produto e local da compra são considerados fundamentais. Em contrapartida, para Brisola e Castro (2005), a comodidade e a praticidade oferecidas pelos pontos de compra são atributos valorizados pelos consumidores de carne; eles ainda afirmam que a proximidade da residência é uma qualidade bastante valorizada pelos consumidores de faixa de renda intermediária.

Tabela 2 - Atributos que influenciam o consumidor durante a consumo/compra da carne suína

$\begin{array}{lcc}\text { VARIÁVEL } & \text { MASCULINO } & \text { FEMININO } \\ & 134 / 255 & 121 / 255\end{array}$

\section{Carne com maior benefício para saúde}

Bovino

$(\%)$

Frango

Suíno

17,2

Peixe

Ovino

Não respondeu 


\begin{tabular}{|c|c|c|}
\hline VARIÁVEL & $\begin{array}{l}\text { MASCULINO } \\
134 / 255\end{array}$ & $\begin{array}{l}\text { FEMININO } \\
121 / 255\end{array}$ \\
\hline Corte de carne suína que mais gosta & & \\
\hline Costela & 58,2 & 51,3 \\
\hline Pernil & 8,2 & 7,4 \\
\hline Bisteca & 5,2 & 9,9 \\
\hline Picanha & 14,2 & 14,0 \\
\hline Lombo & 8,2 & 9,1 \\
\hline Miúdos & 0,0 & 0,0 \\
\hline Não respondeu / não gosta & 6,0 & 8,3 \\
\hline Corte de carne suína que mais compra & & \\
\hline Costela & 56,0 & 52,8 \\
\hline Pernil & 15,7 & 5,8 \\
\hline Bisteca & 11,2 & 14,9 \\
\hline Picanha & 3,7 & 5,8 \\
\hline Lombo & 6,7 & 11,6 \\
\hline Miúdos & 0,0 & 0,8 \\
\hline Não respondeu / não compra & 6,7 & 8,3 \\
\hline Por que você compra/consome este corte? & & \\
\hline Preço & 9,1 & 5,7 \\
\hline Menos gordura & 13,4 & 20,7 \\
\hline Sabor & 52,2 & 41,3 \\
\hline Facilidade de preparo & 13,4 & 20,7 \\
\hline Não respondeu / outros & 11,9 & 11,6 \\
\hline Procedência de compra da carne suína & & \\
\hline Açougue & 12,6 & 7,4 \\
\hline Frigorífico & 4,5 & 1,7 \\
\hline Supermercado & 70,9 & 72,7 \\
\hline Direto do produtor & 1,5 & 3,3 \\
\hline Produção própria & 4,5 & 5,8 \\
\hline Não respondeu / outros & 6,0 & 9,1 \\
\hline $\begin{array}{l}\text { Por que escolheu este lugar para a compra da carne } \\
\text { suína? }\end{array}$ & & \\
\hline Higiene & 14,2 & 13,2 \\
\hline Confiança & 27,6 & 16,5 \\
\hline Proximidade & 9,0 & 20,7 \\
\hline Preço & 10,4 & 5,8 \\
\hline Facilidade & 32,1 & 33,9 \\
\hline Não respondeu / outros & 6,7 & 9,9 \\
\hline
\end{tabular}

A aparência clara foi considerada a característica que mais influencia o grau de qualidade da carne suína para os homens (37,3\%). Já para as mulheres (39,7\%), foi citada a menor quantidade de gordura visível. Ambos os sexos, afirmam que a carne suína deve estar refrigerada de forma adequada para a eleição deste produto no supermercado (Tabela 3). Estes dados estão de acordo com os encontrados por Verbeke et al. (2005), onde a aparência do produto também foi um fator muito importante no momento da compra. Por outro lado, Fonseca e Salay (2008) e Brewer et al. (2001) verificaram que os atributos relacionados que o teor de gordura, colesterol e o valor calórico mostraram maior influência sobre a intenção de consumo da carne suína. Desta forma, pode-se inferir que no momento da aquisição da carne suína, a quantidade de gordura visível é o mais forte estímulo discriminativo no processo de escolha, principalmente quando visualizado na gôndula do supermercado. 
Outrossim, ressalta-se que $29,8 \%$ do total de entrevistados afirmou que o fator mais importante na diferenciação da origem da carne suína está atrelado ao método de produção colonial, ou seja, eles consideram este método como o melhor para obtenção de uma carne de qualidade. Este dado é preocupante, pois tal produção leva em conta o predomínio de mão-de-obra familiar e neste caso, devido ao pequeno tamanho das propriedades é comum que uma grande quantidade de dejetos seja aplicada sobre o solo, sem passar por qualquer tipo de tratamento ou estabilização e sem levar em consideração critérios agronômicos e legais (Kunz et al., 2005).

Diversos autores (Kunz et al., 2004) já evidenciaram o comprometimento da qualidade das águas na região do oeste do Estado de Santa Catarina. Estes resultados sugerem que seja realizado um incremento e aplicação de tecnologias alternativas de manejo e tratamento de dejetos, os quais minimizem o volume e a concentração de poluentes gerados pelo setor, de forma a promover o desenvolvimento sustentável da suinocultura.

Tabela 3 - Atributos que o consumidor considera importante no momento da compra da carne suína

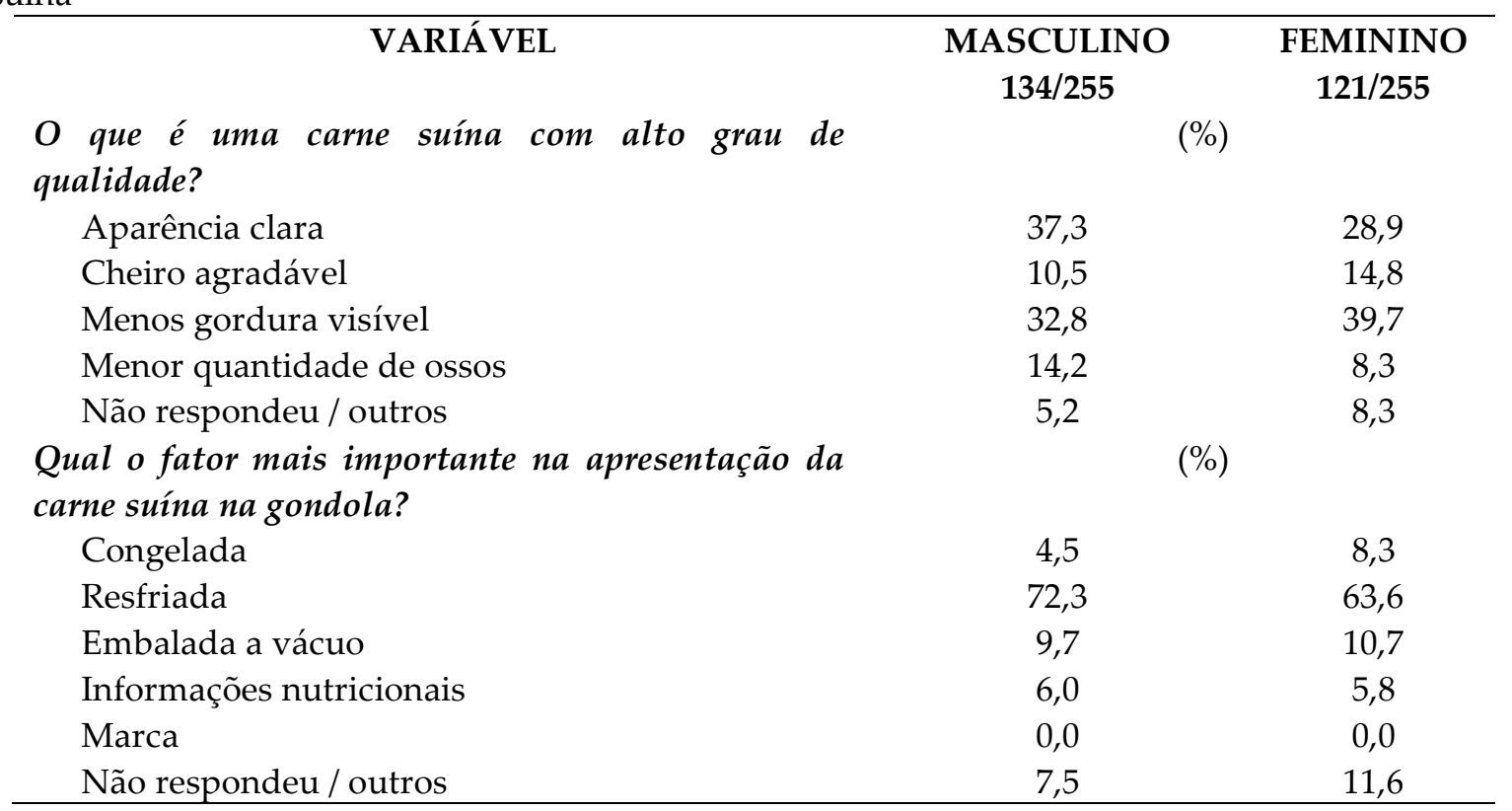

Tendo em vista os resultados obtidos, constata-se que existe um longo caminho a ser percorrido. Deve-se superar os anos e gerações de preconceitos e "tabus", onde visualizou-se o crescimento no consumo das carnes concorrentes. Merlini, et al. (2014) cita que a frequência de consumo de carne suína poderia ser aumentada, a partir da realização de campanhas locais, a fim de melhor esclarecer e informar os consumidores; pois grande parte dos entrevistados que consomem este proteína animal são apreciadores do seu sabor e não consideram apenas o preço como empecilho para o consumo. Além disso, seria necessário realizar campanhas competentes de marketing a fim de obter o sucesso na transmissão destas vantagens ao público consumidor de produto.

Portanto, aconselha-se investir em ações que demonstrem os principais fatores socioeconômicos envolvidos no consumo da carne suína, além de estudos que analisem a qualidade do produto e o real impacto ambiental gerado com a sua produção, a fim de mostrar para a sociedade a importância das constantes mudanças que afetam o setor produtivo e o consumo dos alimentos.

\section{Conclusões}

A costela foi o principal corte de carne suína consumida pela população de Xanxerê.

Para os entrevistados uma carne de qualidade seria aquela com aparência mais clara e menor quantidade de gordura visível. E grande parte dos questionados possuía um bom nível socioeconômico quando comparado a média brasileira. 


\section{Agradecimentos}

Agradecemos ao apoio financeiro concedido pelo Edital 07/Unoesc-R/2014 através da instituição Universidade do Oeste de Santa Catarina (UNOESC).

\section{Referências}

ABIPECS (Associação Brasileira da Indústria Produtora e Exportadora de Carne Suína). Exportação mundial de carne suína. 2014. Disponível em: <http://www.abipecs.org.br/pt/estatisticas/mundial/exportacao.html>. Acesso em: 17 de mar. 2014.

Antonangelo, A. et al. Perfil dos consumidores de carne suína no município de Botucatu - SP. Tékhne $\varepsilon$ Lógos, Botucatu, v. 2, n. 2, 2011.

Barbetta, P. A. Estatística Aplicada às Ciências Sociais. 7. ed. Florianópolis: Editora da UFSC, 2008. $315 \mathrm{p}$.

Barcellos, J.O.J. et al. Consumer perception of Brazilian traced beef. Revista Brasileira de Zootecnia, v. 41, p. 771-774, 2012.

Bezerra, J.M.M. et al. Caracterização do consumidor e do mercado da carne suína na microrregião de Campina Grande, Estado da Paraíba. Ciência Animal Brasileira, v. 8, n. 3, p. 485-494, 2007.

Brewer, M.S.; Zhu, L.G.; Mckeith, F.K. Marbling effects on quality characteristics of pork loin chops: consumer purchase intent, visual and sensory characteristics. Meat Science, v. 59, n. 2, p. 153-163, 2001.

Brisola, M.V.; Castro, A.M.G. Preferências do consumidor de carne bovina do Distrito Federal pelo ponto de compra e pelo produto adquirido. Caderno de Pesquisas em Administração, v. 12, n. 1, p. 81-99, 2005.

CONAB (Companhia Nacional de Abastecimento). Perspectivas para a Agropecuária na Safra 2013/14. Acesso em 18 de mar 2014. Disponível em: http://www.conab.gov.br/OlalaCMS/uploads/arquivos/13_09_12_17_43_13_09_carnes.pdf.

Dias, A.C. et al. Manual Brasileiro de Boas Práticas Agropecuárias na Produção de Suínos. Elaboração de conteúdo Técnico. Brasília, DF: ABCS. Concórdia: Embrapa Suínos e Aves, 2011. 140 p.

FAO (Food and Agriculture Organization). Divisão de produção e sanidade animal. Fontes de carne. $\begin{array}{llllll}\text { Acesso } & \text { em } & 15 & \text { fev. } & 2015 . & \text { Disponível }\end{array}$ http://www.fao.org/ag/againfo/themes/es/meat/backgr_sources.html.

Faria, I.G.; Ferreira, J.M.; Garcia, S.K. Mercado consumidor de carne suína e derivados em Belo Horizonte. Arquivo Brasileiro de Medicina Veterinária e Zootecnia, v. 58, n. 2, p. 251-256, 2006.

Fonseca, M.C.P.; Salay, E. Beef, chicken and pork consumption and consumer safety and nutritional concerns in the City of Campinas, Brazil. Food Control, v. 19, n. 11, p. 1051-1058, 2008.

IBGE (Instituto Brasileireo de Geografia e Estatítica). Cidades. Santa Catarina - Xanxerê, dados completos. Acesso em 12 de dez. 2014. Disponível em: http://www.cidades.ibge.gov.br/xtras/perfil.php?lang=\&codmun=421950\&search=santacatarina\%7Cxanxere.

Grunert, K.G. Future trends and consumer lifestyles with regard to meat consumption. Meat Science, v. 74, p. 149-160, 2006. 
Kunz, A. et al. Recomendações técnicas para uso de esterqueiras para a armazenagem de dejetos de suínos. Comunicado Técnico, Concórdia: Embrapa Suínos e Aves, n. 361, p. 1-4, 2004.

Kunz, A. et al. Tecnologias de manejo e tratamento de dejetos de suínos estudadas no Brasil. Cadernos de Ciência \& Tecnologia, v. 22, n. 3, p. 651-665, 2005.

Levy, P. S.; Lemeshow, S. Sampling of populations, solutions manual: methods and applications. 4 ed. Wiley: New York, USA. 2009.

Merlini, S.L. et al. Caracterização do consumidor e do mercado da carne suína no município de Umuarama - Paraná - Brasil. Enciclopédia biosfera, v. 10, n. 18; p. 833-839, 2014.

Roppa, L. Perspectivas da produção mundial de carnes, 2006 a 2030. Revista Suinocultura Industrial, v. 34, p. 16-27, 2011.

Rubin, L.S.; Ilha, A.S.; Lopes, T.A.M. Exportações de carne suína: performance e possibilidades frente a eliminação de barreiras. Organizações Rurais \& Agroindustriais, Lavras, v. 14, n. 1, p. 28-45, 2012.

Sales, L.E.M. et al. Avaliação da carne suína in natura comercializada em Mossoró-RN. Acta Veterinaria Brasilica, v. 7, n. 4, p. 306-310, 2013.

Santos, T.M.B. et al. Diagnóstico do perfil do consumidor de carne suína no município de Aquidauana-MS. Revista Brasileira de Saúde e Produção Animal, v. 12, n. 1, 2011.

Santos, E.L. Mercado consumidor de carne suína e seus derivados em Rio Largo-AL. Acta Veterinaria Brasilica, v. 6, n. 3, p. 230-238, 2012.

Sarcinelli, M.F.; Venturini, K.S.; Silva, L.C. Características da carne suína. Universidade Federal do Espirito Santo - UFES. Boletim Técnico: 00907 - Editado: 25/08/2007.

Sehnem, S.; Garrido, L. R. A suinocultura e o meio ambiente: estudo de casos no oeste de Santa Catarina. Revista de Administração, v. 3, n. 4, p. 157-176, 2013.

Schlindwein, M.M.; Kassouf, A.L. Análise da influência de alguns fatores socioeconômicos e demográficos no consumo domiciliar de carnes no Brasil. Revista de Economia e Sociologia Rural, v. 44, n. 3, p. 549-572, 2006.

Silva, J.P.; Silva, L.P.G. da. Estudo e avaliação do consumidor de carne suína "in natura" e industrializada na microrregião de Guarabira-PB. Agropecuária Científica no Semiarido, v. 5, n. 1, p. 57-61, 2009.

Soares, L; Belo, M.A.A. Consumo de pescado no município de Porto Velho-RO. Enciclopédia Biosfera, v. 11, n.21, 3059-3067, 2015.

TaffareL, R.T. et al. Mercado consumidor de carne suína e derivados no município de Lavras, Minas Gerais. Revista Eletrônica de Pesquisa Animal, v. 01, n. 01, p. 51-61, 2013.

Thoms, E. et al. Perfil de consumo e percepção da qualidade da carne suína por estudantes de nível médio da cidade de Irati, PR. Revista Acadêmica: Ciências Agrárias e Ambientais, v. 8, n. 4, p. 449-459, 2010.

Trespalacios, J.A.; Vázquez, R.; Bello, L. Investigación de mercados, métodos de recogida y análisis de información para la toma de decisiones en marketing. Thomson: Madrid, Spain. 2005.

Weydmann, C.L. et al. Cadeia produtiva suinícola. In: CARIO, S. A. F. et al. Economia de Santa Catarina: inserção industrial e dinámica competitiva. Florianópolis: Nova Letra, 2008. p. 509-536.

Verbeke, W.; Vackier, I. Profile and effects of consumer involvement in fresh meat. Meat Science, v. 67, p. 159-168, 2004. 